\title{
Pemanfaatan Media E-Learning Sebagai Pendukung Pembelajaran Bagi Guru - Guru SMP N 30 Semarang
}

\author{
Danang Wahyu Utomo ${ }^{1}$, Egia Rosi Subhiyakto ${ }^{2}$, Liya Umaroh ${ }^{3}$ \\ 1,2,3 Universitas Dian Nuswantoro, \\ Fakultas Ilmu Komputer; \\ Jl. Imam Bonjol 207 \\ e-mail: *1danang.wu@dsn.dinus.ac.id, 2egia@dsn.dinus.ac.id, \\ liya.umaroh@dsn.dinus.ac.id
}

\begin{abstract}
Abstrak
Perkembangan teknologi memberikan pengaruh bagi dunia pendidikan. Perlu adanya perubahan metode pengajaran agar pembelajaran lebih interaktif. Para siswa saat ini tidak asing lagi akan teknologi internet, mobile system dan social media. Para guru perlu mengimbangi perkembangan teknologi dari siswanya tersebut. Pembelajaran online bukan lagi pembelajaran yang baru di sekolah - sekolah. Banyak sekolah yang menerapkan pembelajaran online yaitu salah satunya e-learning. Namun masih ada juga sekolah yang masih menggunakan pembelajaran konvensional. Salah satunya adalah SMP N 30 Semarang. SMP $N$ 30 Semarang memiliki infrastruktur yang memadai seperti computer, internet dan server. Namun belum digunakan secara maksimal dalam proses Kegiatan Belajar Mengajar. Para guru masih kesulitan dalam menerapan pembelajaran online dalam kelasnya. Perlu adanya pendampingan dalam penggunaan sistem e-learning. Sebelumnya, sistem e-learning telah diusulkan namun masih belum maksimal dalam penggunaannya. para guru masih kesulitan dalam menggunakan dan menerapkan sistem pada siswa. Perlu adanya sosialisasi ulang untuk mendapatkan pemahaman khusus dalam proses pembelajaran online. Peneliti mengusulkan pengabdian tentang optimalisasi pemanfaatan e-learning dimana pengabdian ini diharapkan mampu memberikan pemahaman khusus dasar e-learning dan bagaimana proses pengisian konten dilakukan.
\end{abstract}

Kata kunci-E-Learning, Pembelajaran, Guru, Siswa

\begin{abstract}
Technological developments have an impact on education. It is necessary to change teaching methods to make learning more interactive. Students today are familiar with internet technology, mobile systems and social media. Teachers need to balance the technological developments of these students. Online learning is no longer a new learning in schools. Many schools that implement online learning is one of them e-learning. But there are still schools that still use conventional learning. One of them is SMP N 30 Semarang. SMP N 30 Semarang has adequate infrastructure such as computer, internet and server. But it has not been used maximally in the process of Teaching and Learning Activities. Teachers are still struggling to apply online learning in their classes. Need assistance in the use of e-learning system. Previously, e-learning system has been proposed but still not maximal in its use. Teachers still find it difficult to use and apply the system to students. Needs re-socialization to gain a special understanding in the online learning process. The researcher proposes dedication on optimizing the utilization of e-learning where the devotion is expected to provide basic understanding of $e$ learning and how the content filling process is done.
\end{abstract}

Keywords - E-learning, learning, teacher, student 


\section{PENDAHULUAN}

Guru memiliki peran penting dalam mengembangkan proses pembelajaran. Guru tidak hanya mengajar siswa tetapi juga bertugas dalam membina, memberi contoh, dan mengevaluasi. Oleh karena itu, guru dituntut untuk mampu mengembangkan kemampuannya meliputi tiga aspek yaitu kognitif, afektif dan psikomotorik. Tentunya pengembangan diri tidak lepas dari infrastruktur pendukung dari sekolah. Perlu adanya peran pendukung kepada guru untuk meningkatkan tiga aspek pembelajaran tersebut seperti media pembelajaran (whiteboard, projector, peta, komputer). Jika guru masih menggunakan cara konvensional dalam mengajar yaitu pembelajaran satu arah, siswa hanya mendengarkan apa yang guru jelaskan. Akibatnya, tidak semua siswa dapat memahami apa yang guru jelaskan dikarenakan siswa mulai bosan, ngantuk, bahkan suka berbicara dengan teman sebelahnya. Perlu adanya inovasi dalam pembelajaran di kelas.

Perkembangan teknologi saat ini menjadi pengaruh dalam dunia pendidikan. Teknologi yang berkembang membawa pengaruh bagi metode pengajaran dalam pendidikan formal seperti SD, SMP, SMA, dan Perguruan Tinggi. Mayoritas sekolah - sekolah saat ini menggunakan alat bantu untuk membantu pengajar dalam proses kegiatan belajar mengajar (KBM) di kelas. Seperti [1] mengusulkan alat bantu berupa web based system yang bertujuan membantu pembelajaran kelompok dalam kelas, [2] mengusulkan penilaian dalam pembelajaran kelompok yang sesuai terhadap tugas yang diberikan oleh guru. Saat ini, penerapan e-learning menjadi alat bantu utama dalam penyelenggaraan pembelajaran di sekolah.

E-learning mampu membantu para pengajar dalam memberikan inovasi dalam proses belajar mengajar di kelas. Guru dapat memantau perkembangan dari siswanya, guru dapat mengatur pemberian tugas secara berkala, dan siswa pun dapat selalu mengecek nilai yang diperoleh selama pembelajaran. Namun, permasalahan yang terjadi saat ini adalah mayoritas para pendidik masih beranggapan bahwa metode konvensional masih metode paling baik dalam proses KBM. Pendidik memiliki anggapan bahwa pembelajaran yang baik adalah pembelajaran yang bertatap muka, siswa mendengarkan dan memahami apa yang guru jelaskan, dan siswa diharuskan bertanya jika masih bingung dengan materi yang dijelaskan. Selain itu, kendala yang kedua adalah usia yaitu mayoritas para pendidik yang sudah tua lebih memilih metode yang selama ini digunakan daripada harus mempelajari lagi teknologi baru (e-learning). [3] menyatakan bahwa aspek manusia penting dalam penyelenggaraan KBM. Motivasi, kognitif, dan profesionalitas penting dalam meningkatkan kualitas belajar siswa. Seorang pendidik seharusnya mampu memberikan inovasi dan mengikuti perkembangan teknologi yang telah berkembang. Para siswa saat ini sudah familiar dengan perkembangan teknologi saat ini. Mayoritas siswa sudah mengenali perkembangan internet, memiliki smartphone, dan sosial media sebagai komunikasi. Para guru harus mampu mengikuti perkembangan teknologi seperti siswanya, hal ini bertujuan agar para guru mampu mendampingi siswanya agar tidak menyalahgunakan teknologi yang digunakan. Kendala selanjutnya adalah infrastruktur pendukung, sekolah harus mampu menyediakan alat - alat pendukung dalam pengembangan pembelajaran. Seperti computer, internet, dan server merupakan alat yang seharusnya dimiliki oleh sekolah. Jika infrastruktur dapat dialokasikan, maka kendala diatas mampu diatasi dan hasilnya sekolah dapat meningkatkan pembelajaran yang berkualitas. E-learning dapat diselenggarakan dengan baik di sekolah tersebut.

SMP N 30 Semarang adalah salah satu sekolah negeri di Semarang yang berupaya meningkatkan kualitas proses KBM. SMP N 30 Semarang telah meningkatkan infrastruktur pendukung seperti adanya lab komputer dan server. Artinya, SMP N 30 memiliki infrastruktur yang memadai untuk menyelenggarakan e-learning. Sistem e-learning sudah diusulkan pada SMP N 30 Semarang yaitu penggunaan moodle yang telah dimodifikasi dan disesuaikan untuk tingkat SMP. Sistem berbasis web yang ditujukan kepada guru - guru dengan tujuan guru guru tidak lagi kesulitan dalam memberikan materi dan tugas kepada siswanya. Bagi siswa, dapat memantau nilai yang diperoleh selama pembelajaran. Namun, kendala sebelumnya 
(kendala kedua) yaitu para guru masih kesulitan dalam memahami konsep e-learning. Para guru masih kesulitan menemukan dasar dan referensi dalam penggunaan e-learning di sekolah terutama tingkat SMP. Selain itu, konten pada e-learning sebelumnya masih belum diterapkan semua. Masih ada modul - modul yang kosong, belum di isi oleh pihak SMP N 30. Hal ini menunjukkan sistem e-learning belum dijalankan sepenuhnya oleh guru - guru SMP N 30 Semarang.

Berdasarkan permasalahan diatas, perlu adanya tindak lanjut kembali dalam penggunaan sistem e-learning yang telah diusulkan. Perlu adanya pendampingan dan pemahaman bagi guru - guru agar dapat menjalankan e-learning tersebut. Oleh karena itu, kami para peneliti mengusulkan pengabdian di SMP N 30 Semarang untuk memberikan pendampingan dan materi - materi pembelajaran yang digunakan dalam e-learning. Adanya pendampingan dan pemberian materi e-learning diharapkan para guru lebih memahami dasar e-learning dan pembelajaran lebih interaktif antara guru dan siswa. Guru lebih bermotivasi dalam memberikan inovasi KBM dan siswa lebih semangat dalam belajar.

\section{METODE PELAKSANAAN}

Pelaksanaan pengabdian masyarakat menggunakan tahapan sebagai berikut:

1. Koordinasi ulang dengan pihak SMP Negeri 30 Semarang yang terdiri dari Kepala sekolah dan wakil Sekolah untuk menentukan mekanisme pelaksaan pengabdian masyarakat.

2. Penyusunan materi pengabdian masyarakat.

3. Penyusunan simulasi penggunaan e-learning.

4. Penyebaran undangan pelatihan ke guru-guru SMP Negeri 30 Semarang.

5. Persiapan teknis (infrastruktur) antara lain: komputer, perangkat dokumentasi, backdrop, konsumsi, materi simulasi, dan daftar hadir.

6. Persiapan website dalam bentuk moodle, koneksi internet, simulasi penggunaan

7. Dokumentasi yang bersifat administratif sebagai penyusunan laporan pertanggungjawaban.

\section{HASIL DAN PEMBAHASAN}

Pada pengabdian masyarakat ini, kami menggunakan alat bantu moodle sebagai media e-learning untuk memberikan media pembelajaran online bagi SMP N 30 Semarang. Pengabdian ini merupakan program lanjutan dari pengabdian masyarakat tahun 2017, dimana tim pengabdian masyarakat masih membahas materi secara global tentang penggunaan elearning pada level SMP.

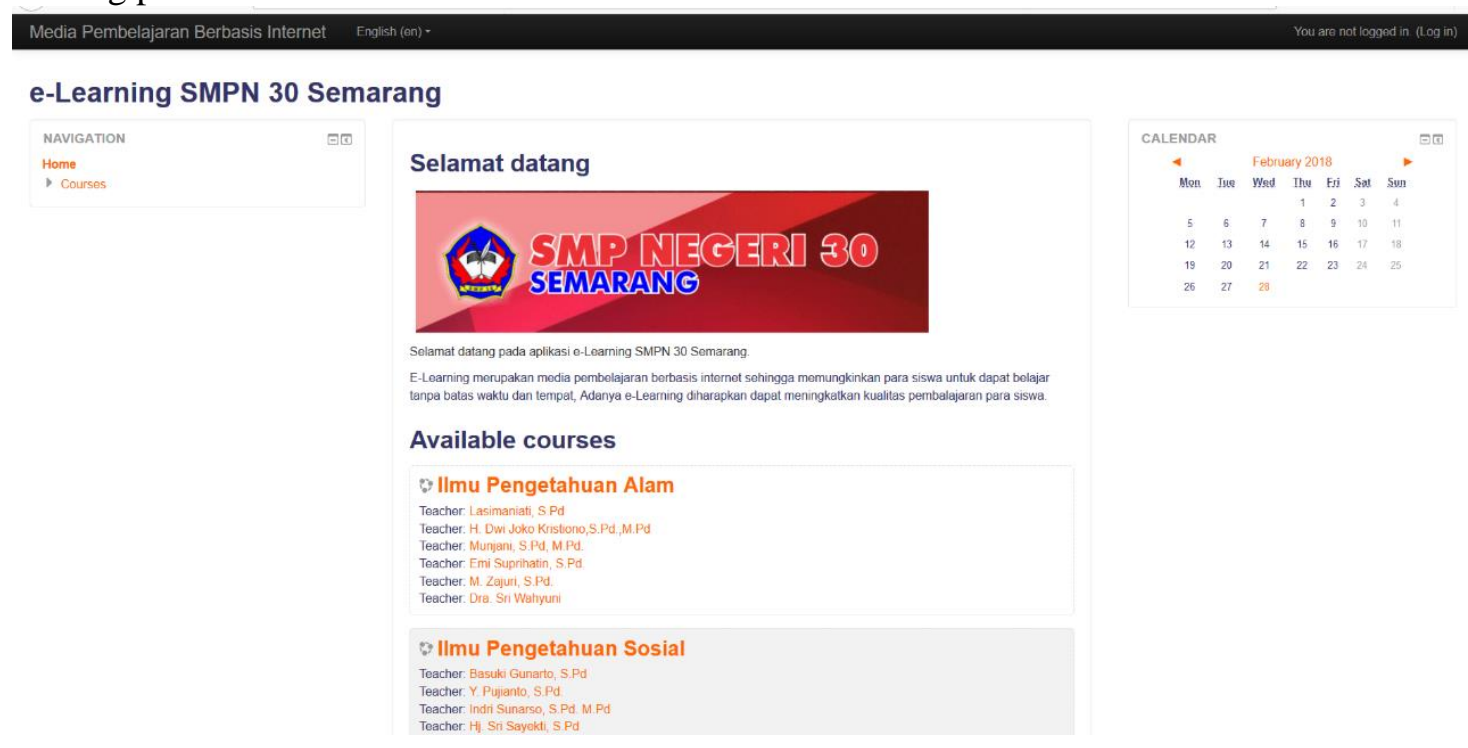




\section{Gambar 1 Interface E-Learning}

Tampilan awal aplikasi web e-learning (Gambar 1) menampilkan beberapa mata pelajaran yang telah di sesuaikan oleh mata pelajaran yang di ampu oleh guru. Masing - masing guru memiliki akun yang digunakan sebagai akses masuk ke halamannya.

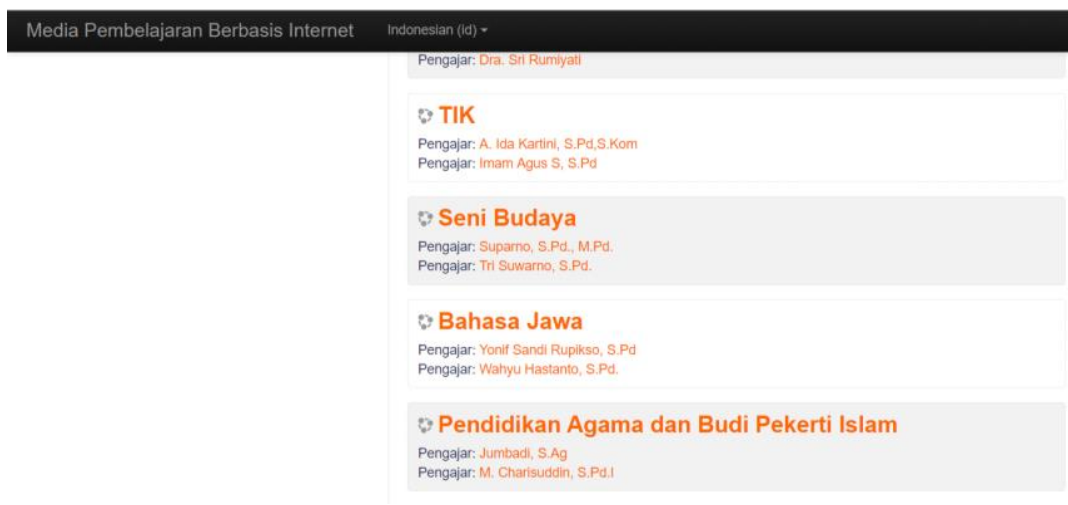

Gambar 2 Pengaturan Topik Pembelajaran

TIK

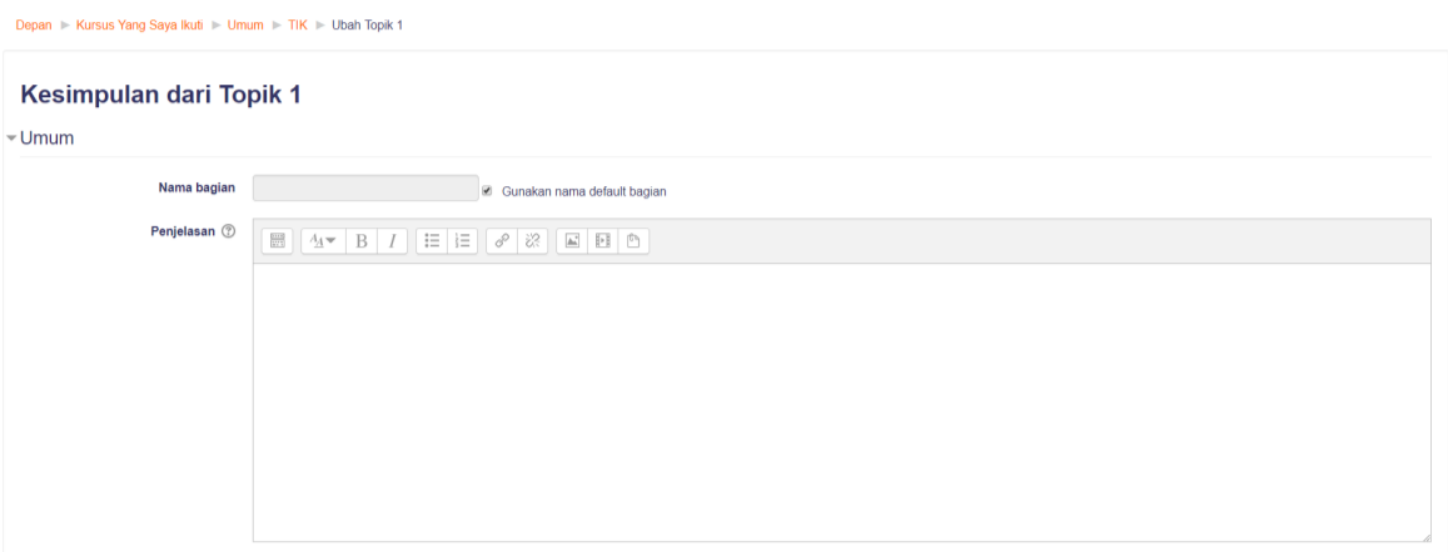

Gambar 3 Pengisian Topik

Setelah berhasil melakukan akses ke halaman guru, para guru dapat mengatur topik pembelajaran tiap minggunya (gambar 2). Hal ini memudahkan bagi siswa untuk belajar di rumah dimana aplikasi telah menyediakan fasilitas pembahasan materi dan penugasan. Jadi para siswa yang masih bingung tentang materi yang diajarkan, dapat mempelajari kembali. Pada gambar 3, menampilkan formulir untuk memberikan pengisian topik tiap minggunya. Bagian ini di desain hanya 2 field, tujuannya untuk mempermudah para guru yang sudah tua agar tidak banyak mengingat dalam mengisi topik pembelajaran.

Pada materi selanjutnya, kami membahas mengenai diskusi online guna memfasilitasi siswa dan guru dalam berdiskusi meskipun tidak bertatap muka. Forum ini juga melatih siswa untuk berani mengungkapkan pendapat dan pertanyaannya kepada guru - gurunya. Selain itu, para guru dapat memantau apakah siswanya benar - benar aktif dalam pembelajaran online. Gambar 3 menampilkan forum diskusi bagi siswa dan guru dalam pembelajaran online. guru dapat menambahkan materi diskusi guna menambah referensi bagi siswanya. 


\section{IPA Terpadu}

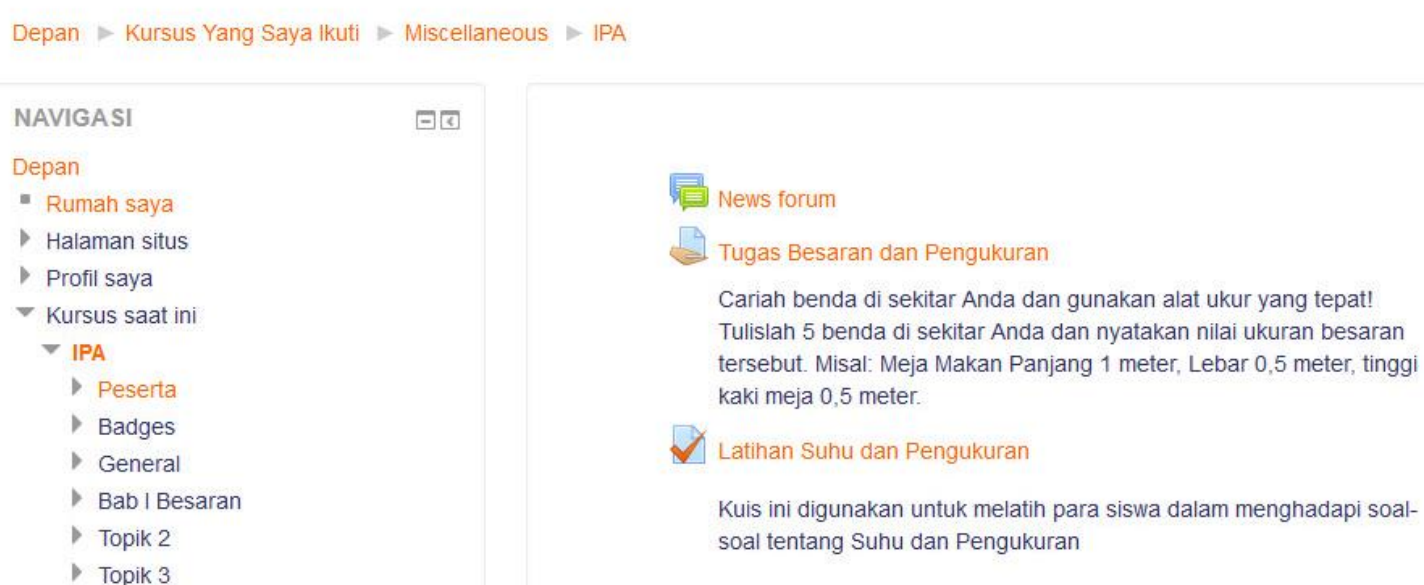

Gambar 4 Diskusi Online

\section{KESIMPULAN}

Guru merupakan pendidik profesional yang memiliki tugas utama mendidik, mengajar, membimbing, mengarahkan, melatih, menilai, dan mengevaluasi peserta didik. Maka IBM ini diperuntukkan untuk guru-guru di SMPN 30 Semarang untuk dapat lebih mengenal dan memanfaatkan e-Learning sebagai media pembelajarannya. Sehingga pihak sekolah memiliki kesadaran untuk menerapkan aplikasi e-Learning. Dan para siswa lebih siap dalam menghadapi ujian berbasis komputer. Pelaksanaan pengabdian ini akan memberikan pendampingan dan pengenalan dalam memanfaatkan e-Learning untuk memberikan tugas dan materi ajar. Tersedianya forum diskusi mata pelajaran sebagai media siswa untuk bertanya ataupun berkonsultasi kepada guru pengampu mata pelajaran. Dan mengimplementasikan simulasi ujian online yang dibuat oleh para guru mata pelajaran yang bisa digunakan untuk mengasah pemahaman para siswa dalam mempersiapkan ujian nasional

\section{SARAN}

Pada pengabdian masyarakat selanjutnya, perlu adanya penambahan fitur seperti model pembelajaran kelompok melalui media online, penilaian yang adil bagi siswa guna membantu guru dalam menilai pembelajaran kelompok, dan ada forum diskusi interaktif yang bertujuan menampung pertanyaan dari siswa.

\section{DAFTAR PUSTAKA}

[1] D. W. Utomo et al., "Tool Enhancement For Collaborative Software Engineering Education," Semin. Nas. Teknol. Inf. dan Komun. 2015 (SENTIKA 2015), pp. 9-16, 2015.

[2] D. W. Utomo and E. R. Subhiyakto, "Assessing Novice Teams in Collaborative Software Engineering Education,” Semin. Nas. Apl. Teknol. Inf. 2016, pp. 23-28, 2016.

[3] I. Hadar, S. Sherman, and O. Hazzan, "Learning human aspects of collaborative software development," J. Inf. Syst., no. 1, 2008. 